\title{
Crimes Corporativos: Explorando o dark side das organizações
}

\author{
Cintia Rodrigues de 0. Medeiros | cintia@fagen.ufu.br
}

Os estudos sobre organizações, predominantemente, enfatizam o seu lado positivo, tratando as manifestações negativas como excepcionais, e não como parte das suas práticas. Porém, erros, acidentes e crimes são, frequentemente, protagonizados por organizações na busca de seus objetivos, resultando em prejuízos a consumidores, trabalhadores, meio ambiente e comunidades. Todavia, a produção desses fenômenos, principalmente dos crimes corporativos, tem sido negligenciada como objeto de estudos no campo da Gestão e Organizações, o que implica lacunas a serem preenchidas. Para iniciar uma incursão na literatura sobre o assunto, a professora Cintia Rodrigues de $\mathbf{0}$. Medeiros, da Faculdade de Gestão e Negócios da Universidade Federal de Uberlândia (FAGEN/UFU), indica cinco obras fundamentais, que ajudam a alcançar uma compreensão sociológica dos conceitos, tipos e abordagens de crimes corporativos.
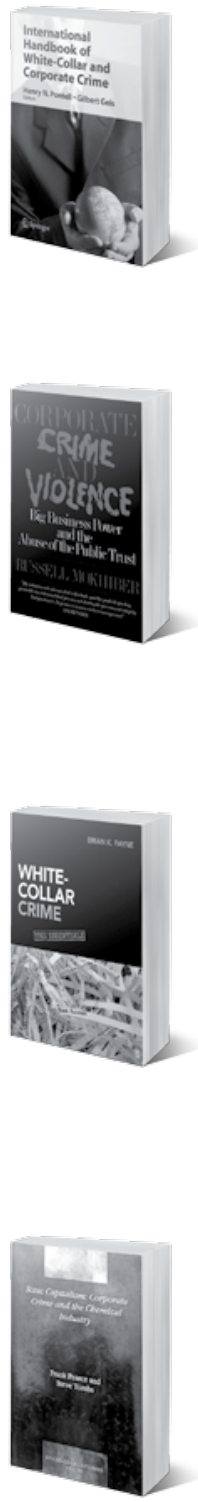

\section{INTERNATIONAL HANDBOOK OF WHITE-COLLAR AND CORPORATE CRIME}

Henry N. Pontell e Gilbert Geis. New York: Springer, 2007. 720 p.

0 Handbook reúne 34 artigos organizados em 11 partes, que exploram teorias do crime, análises históricas e sociológicas, perspectivas teóricas e legais, a justiça criminal, o papel da mídia, entre outros temas relacionados. Com variadas abordagens, os artigos não se limitam a estudos norte-americanos, incorporando pesquisas realizadas na Ásia, Europa e Austrália. Espera-se que a leitura desta obra estimule reflexões sobre as consequências nefastas dos diversos tipos de crimes corporativos.

\section{CORPORATE CRIME AND VIOLENCE: Big businesS power and the abuse of the public trust}

Russell Mokhiber. New York: Random House, 1989. 450 p.

Esta obra lista 36 crimes corporativos de diferentes tipologias, como a fabricação de produtos prejudiciais, poluição ambiental e corrupção, envolvendo a negligência e ganância de indústrias poderosas. 0 estudo investigativo alerta para os riscos e perigos a que as corporações expõem a sociedade, o que exige a reformulação de leis sobre responsabilização e punição. Além de discutir aspectos conceituais, Mokhiber oferece 50 sugestões para prevenir e penalizar esses abusos.

\section{WHITE-COLLAR CRIME: The essentials}

Brian Payne. Sage Publications, 2012. 472 p.

Esta recente publicação oferece uma visão didática para uma compreensão ampla do White-collar crime, termo conhecido no Brasil como "crime do colarinho-branco". Payne não distingue esse termo de crime corporativo, um fenômeno não raro, cujas consequências são graves. Diferentes tipos de crimes corporativos são explorados, com a apresentação de textos clássicos e casos ilustrativos. Recomendado para ser utilizado como livro-texto em aulas de gestão contemporânea.

\section{TOXIC CAPITALISM: Corporate crime and the chemical industry}

Frank Pearce e Steve Tombs. Aldershot: Dartmouth, 1998. 372 p.

Procurando desenvolver uma compreensão dos efeitos da indústria, os autores conceituam o capitalismo tóxico. Organizado em três partes, este livro discute a natureza destrutiva das corporações que causa morte, doenças e devastação ambiental. Uma análise da natureza do capitalismo contemporâneo e da corporação como forma de organização de negócios, bem como conceitos e perspectivas de crimes corporativos, conduz a reflexões sobre o papel e a atuação das corporações.

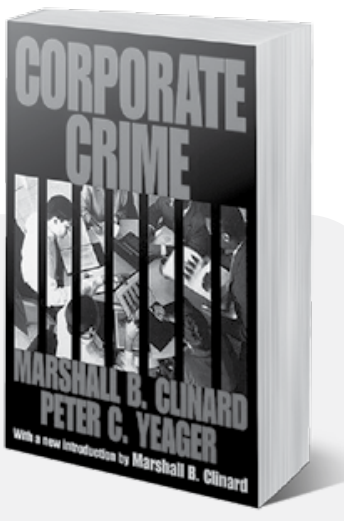

CORPORATE CRIME

Marshall B. Clinard e Peter C. Yeager. New Brunswick: Transaction Publisher, 2006. 387 p.

Este livro apresenta um estudo extenso das violações de grandes corporações norte-americanas, concluindo que informações sobre o desempenho financeiro e as características estruturais são insuficientes para explicar o crime corporativo. Os autores abordam a discussão conceitual sobre o termo crime corporativo, discutem a gravidade das violações corporativas para a sociedade e oferecem explicações acerca do papel desempenhado pelos principais executivos, fatores econômicos, cultura corporativa, o controle e as abordagens alternativas. 